Marcos César Seneda

\title{
The Extra-Logical Strategy Constructed by Kant to Define Concepts and Intuitions as Inversely Polar Representations
}

\section{The Problem}

The reader is generally impressed by the confidence with which Kant begins one of the principal divisions of the Critique of Pure Reason i.e. Transcendental Aesthetics conducted by two procedures named metaphysical exposition and transcendental exposition. Accustomed to the qualifying adjective transcendental - which permeates all of the Critique - we are inclined to believe that only a transcendental exposition could furnish us with something worthy of the term proof since it examines the conditions of the possibility of the two sciences, Mathematics and Physics, to be considered as given. Because of this we can accept as dogmatic the metaphysical exposition, admit that it begins with the decomposition of the concepts (space and time) which we could consider as something originally given, but apparently impossible to analyze (unauflöslich).

We could therefore ask ourselves: how could Kant discursively analyze concepts that would become the basis of transcendental knowledge? Transcendentality in Kant is theoretically circumscribed by the intersection of two sciences: Mathematics and Physics. Then, could space and time be arbitrarily defined in such a way that from this definition there would arise direct consequences for the way in which Mathematics and Physics operate? This is definitely not the case and the answer to this question could only be conceived retrospectively, and it would have to be constructed in various ways.

\section{Two Opposite but Complementary Procedures}

One of these ways used by Kant starts from the point of view of the complementarities of the tasks of the two sciences, Mathematics and Philosophy. Both the

\footnotetext{
Marcos César Seneda, Federal University of Uberlândia (UFU), Brazil, mseneda@ufu.br This paper presents the partial results of a study carried out with the support of FAPEMIG (Research Support Foundation of the State of Minas Gerais, Brazil). I would also like to thank Mr. John Joe O'Connell for his help with the English version of this paper.
} 